Conclusions These data shows considerable variation in outcome trend data across England. COPD mortality has improved in most but not all areas over 17 years. Mortality has improved in more PCTs compared to a reduction in bed-days for COPD and readmissions. Readmissions have increased in more PCTs than the other 2 outcome measures. These variations are unexplained and need investigating. Analysis of trend data for outcomes is essential, for providers and commissioners, to identify services that are improving or deteriorating,

Abstract P287 Table 1 Table of number of PCTs with a trend for improving, remaining stable, and deteriorating in three outcome measures over time

\begin{tabular}{lccc}
\hline Number of PCTs & Mortality & Beddays & Readmissions \\
\hline Improved & 106 & 38 & 3 \\
Stable & 46 & 111 & 122 \\
Deteriorated & 0 & 2 & 25 \\
\hline
\end{tabular}

\section{P288 A UNIFIED RANKING SYSTEM FOR KEY COPD OUTCOME MEASURES SHOWING VARIATION BETWEEN PCTS AND HOSPITALS-HELPING TO DRIVE CHANGE}

doi:10.1136/thoraxjnl-2012-202678.380

${ }^{1} \mathrm{AG}$ Davison, 'L Jongepier, ${ }^{2} \mathrm{JR}$ Flowers, ${ }^{2} \mathrm{~K}$ Smith. ${ }^{1} \mathrm{NHS}$ Midlands and East, Cambridge, England; '2uality Intellegence East, Eastern Public Health Observatory, Cambridge, England

The White Paper "Equity and Excellence. Liberating the NHS" stated that the health service must be focused on outcomes and quality standards that deliver them. INHALE (Interactive Health Atlas for Lung in UK), www.inhale@nhs.uk.contains over 70 outcome measures for all the Regions and PCTs in UK. Demonstrating variation in outcomes drives service change. Hospital mortality has been reduced using this methodology. Wright J, Dugdale B, Hammond I et al Learning from death. A hospital mortality reduction programme. JRSM 2006; 99: 303-308.

Methods Four key outcome measures which reflect hospital, community and primary care of COPD have been selected from INHALE These are COPD mortality rate per 100,000 PCT population 200810 , hospital bed-days per 1000 population $2010-11$, \% hospital readmissions within 28 days for COPD 2010-11, ratio of expected to observed COPD cases over the PCT for 2010-11. An action list of COPD service improvements has been prepared by the EoE Respiratory Team.
Results There is considerable variation for each outcome measure across the East of England (EoE). 2.04 fold for mortality, 2.61 fold for bed-days, 1.67 fold for hospital readmissions and 1.56 for Observed/Expected. These measurements have been ranked across the PCTs. The ranking of these 4 outcome measures have been summated and then ranked to give an overall PCT ranking. The Table shows ranking of each outcome measure and unified summated ranking.

Conclusion The wide variation in outcomes across the EoE has been more clearly demonstrated by using a ranking system. An EoE data pack has been produced demonstrating this and includes the overall ranking, bar charts and funnel plots of the outcome measures, a trend analysis of the outcome measures, and the suggested service improvements. This has been circulated to all respiratory consultants, CCG leads, local respiratory networks, and hospital chief executives in the Region. This allows comparisons to be made and helps to drive change. Localities and hospitals have started to draw up service improvements.

\section{P289 FINDING THE MISSING MILLIONS - THE IMPACT OF A LOCALLY ENHANCED SERVICE FOR COPD ON CURRENT AND PROJECTED RATES OF DIAGNOSIS}

doi:10.1136/thoraxjnl-2012-202678.381

${ }^{1} \mathrm{C}$ Falzon, ${ }^{2} \mathrm{M}$ Soljak, ${ }^{3} \mathrm{SL}$ Elkin, ${ }^{1} \mathrm{ID}$ Blake, ${ }^{4} \mathrm{NS}$ Hopkinson. ${ }^{1}$ Central London Community Healthcare, London, UK; '2Department of Primary Care and Public Health, Imperial College, London, UK; ${ }^{3}$ Respiratory Medicine, Imperial College NHS Trust, London, UK; ${ }^{4}$ NIHR Respiratory Disease Biomedical Research Unit at the Royal Brompton and Harefield NHS Foundation TrustImperial College, London, UK

Background Chronic obstructive pulmonary disease (COPD) is a common and important condition but there is a considerable gap between the modelled and diagnosed prevalence of the disease.(1) In 2008 a locally enhanced service (LES) for COPD was introduced in our Primary Care Trust (PCT) which included a small financial incentive for GP's to perform spirometry but a larger one where COPD patients were identified and received additional quality items of care including; spirometry and pulse oximetry; smoking cessation; recording of BMI and MRC dyspnoea score; review of inhaler technique; medication review; provision of a COPD rescue pack if appropriate; issuing a self-management plan; influenza and pneumococcal vaccination. In the first year this encouraged GP's to focus case-finding efforts on those most likely to have COPD and led to a significant step up in the diagnosed prevalence.(2)

Methods To evaluate longer term effects we used annual QOF reporting-year data on prevalence of COPD at PCT level from 2005

Abstract P288 Table 1

\begin{tabular}{|c|c|c|c|c|c|c|}
\hline РCT & $\begin{array}{l}\text { Readmissions within } 28 \text { days } \\
\text { (\%) 2010/11 }\end{array}$ & Mortality 2010 & $\begin{array}{l}\text { Beddays per } 1000 \mathrm{PCT} \\
\text { population } 2010 / 11\end{array}$ & $\begin{array}{l}\text { Ratio of observed: expected } \\
\text { COPD prevalence 2010/11 }\end{array}$ & Ranksum & Summary rank \\
\hline Norfolk & 4 & 2 & 4 & 5 & 11 & 1 \\
\hline Cambridgeshire & 5 & 4 & 6 & 1 & 11 & 2 \\
\hline Mid Essex & 1 & 3 & 2 & 10 & 15 & 2 \\
\hline North East Essex & 2 & 8 & 5 & 3 & 16 & 4 \\
\hline Suffolk & 6 & 1 & 3 & 9 & 13 & 5 \\
\hline Hertfordshire & 7 & 7 & 1 & 6 & 14 & 6 \\
\hline Great Yarmouth and Waveney & 10 & 6 & 8 & 4 & 18 & 7 \\
\hline South West Essex & 3 & 13 & 12 & 2 & 27 & 8 \\
\hline West Essex & 9 & 9 & 9 & 7 & 25 & 9 \\
\hline Bedfordshire & 8 & 12 & 11 & 8 & 31 & 10 \\
\hline Luton & 11 & 5 & 13 & 12 & 30 & 11 \\
\hline Peterborough & 13 & 11 & 7 & 11 & 29 & 12 \\
\hline South East Essex & 12 & 10 & 9 & 13 & 32 & 13 \\
\hline
\end{tabular}




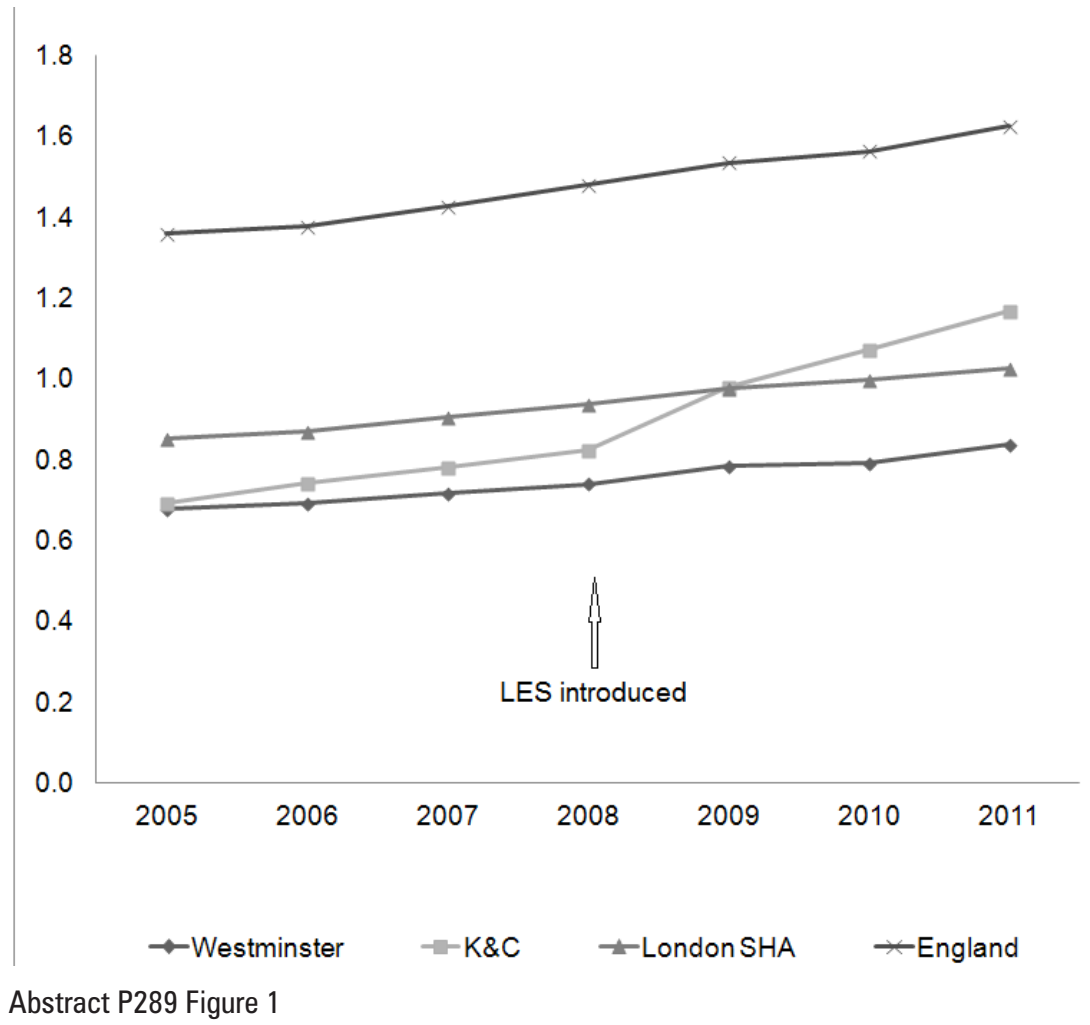

through to March 2011 obtained from the QMAS database via the NHS Information Centre. COPD prevalence data for the 4 years from the introduction of the LES (2008) were used to compare trends in COPD diagnosis between the PCT where it had been introduced, a neighbouring PCT, the London SHA and England. True COPD prevalence was estimated using data from the Health Survey for England. Diagnosed prevalence trends were extrapolated to estimate the year this level would be reached.

Results The rate of increase in COPD diagnosis with the LES remained significantly increased compared to that for London as a whole (Figure 1). Extrapolating 2008-2011 trends in prevalence, the PCT where the LES was in place would be expected to reach the modelled prevalence of COPD in 2030 whereas London as a whole would not reach the true prevalence until 2080.

Conclusion Current strategies for COPD case finding are inadequate given the scale of the problem. With appropriate incentives it is possible to achieve a sustained improvement in case-finding and such policies need to be implemented systematically.

1. Nacul L, Soljak M, Samarasundera E, Hopkinson NS, Lacerda E, Indulkar T, et al. COPD in England: a comparison of expected, model-based prevalence and observed prevalence from general practise data. J Public Health. 2011; 33(1): $108-16$.

2. Falzon C, Elkin SL, Kelly JL, Lynch F, Blake ID, Hopkinson NS. Can financial incentives for improvements in healthcare quality enhance identification of COPD in primary care? Thorax. 2011; 66(7):630.

\section{P290 IMPACT OF A COMBINED ADMISSION AND DISCHARGE COPD CARE BUNDLE ON HOSPITAL MORTALITY AND READMISSION RATES}

doi:10.1136/thoraxjnl-2012-202678.382

A Graham. Huddersfield Royal Infirmary, Huddersfield, UK

Background A care bundle is a group of evidence based interventions which if consistently delivered should improve outcomes.

Published work (Thorax 2012) has demonstrated the impact of a COPD discharge bundle on hospital readmission rates. There is no published information on the use of bundles to address in-hospital mortality for COPD.

Methods In April 2011 a care bundle for acute exacerbation of COPD (AECOPD) was introduced at both acute hospital sites in our Trust. The bundle content was printed on an adhesive sticker which was placed in the case notes. It consisted of a 7 point acute care section, completed on admission, and a 10 point discharge section completed prior to discharge. Multidisciplinary training and intranet guidance was provided to staff. Bundle use and compliance with each element was assessed quarterly through audit of 50 consecutive admissions. Hospital readmission rates and mortality were also reviewed.

Results Audit was undertaken in October 2011, January 2012 and April 2012. Bundle stickers were reliably placed in the medical notes (>80\%). Delivery of all 7 admission bundle elements was high in each audit $(>75 \%)$, but compliance with the timings required fell during the ongoing audit $(56 \% ; 24 \% ; 26 \%)$. Compliance was higher in patients admitted through A\&E compared to those admitted directly to MAU Compliance with all 10 discharge bundle elements initially improved but was not sustained $(26 \%$; $74 \%$; $35 \%$ ). Site specific comparison indicated that discharge bundle delivery was better with a hospital based respiratory specialist nursing "outreach" service, than with a community based "inreach" service. Overall compliance with all 17 bundle elements fell during the year (24\%; $26 \%$; $5 \%$ ). Readmission rates compared to the previous financial year fell from $14.9 \%$ to $12.8 \%$. Mortality rates also fell (figure).

Conclusion Despite the lack of full compliance with the bundle, it was well used and improved outcomes were seen in terms of mortality and readmissions. It was felt that the bundle acted as a focus for improving knowledge and delivery of COPD care. Regular training and encouragement of staff will be required to sustain compliance with use of the bundle. 